\title{
Monocyte Distribution Widths for Early Sepsis Detection in Emergency Department and Comparison with C-reactive Protein and Procalcitonin
}

\author{
Ala woo \\ Asan Medical Center \\ Dong-Kyu Oh \\ Asan Medical Center \\ Chan Jung Park \\ Asan Medical Center \\ Sang-Bum Hong ( $\nabla$ hongsangbum@gmail.com ) \\ Asan Medical Center https://orcid.org/0000-0003-2737-7695
}

Research

Keywords: Sepsis, biomarker, monocyte distribution width, C-reactive protein, procalcitonin

Posted Date: November 20th, 2020

DOl: https://doi.org/10.21203/rs.3.rs-111247/v1

License: (c) (i) This work is licensed under a Creative Commons Attribution 4.0 International License.

Read Full License 


\section{Abstract}

Background: Monocyte undergo morphological changes in response to infection. Monocyte distribution width (MDW) reflects the morphological changes and increase in septic conditions. Currently, it has been suggested that MDW can act as an early biomarker of sepsis, but there are few reports on the comparison with conventional biomarkers such as C-reactive protein (CRP) and procalcitonin (PCT).

Methods: Patients who visited the emergency department (ED) were screened and enrolled prospectively. Tests for complete blood count, MDW, CRP, and PCT were done. Diagnostic performance for sepsis was tested in terms of area under the curve (AUC) of receiver operating characteristic (ROC) curves, sensitivity, and specificity.

Results: In total, 665 patients were screened, and 549 patients with validated laboratory test results were included for the analysis. The patients were categorized into three groups according to Sepsis-3 criteria: non-infection, infection, and sepsis. MDW was the highest in the sepsis group (median [Q1-Q3] 24.0 [20.827.8]). AUC [95\% Cl] for MDW, CRP, PCT, and white blood cells for sepsis were 0.71[0.67-0.75], 0.75[0.71$0.78], 0.76[0.72-0.79]$, and $0.61[0.57-0.65]$, respectively. With the optimal cut-off value from the cohort, the sensitivity was $85.6 \%$ with MDW (cut-off 19.8), $69.7 \%$ with CRP (4.0), and $76.6 \%$ with PCT (0.05). Combination of quick sequential organ failure score (qSOFA) with MDW and WBC improved the AUC $(0.78[\mathrm{Cl} 0.74-0.82])$ to a greater extent compared to qSOFA alone $(0.67[\mathrm{Cl} 0.62-0.72])$.

Conclusions: MDW reflected comparable diagnostic performance with conventional diagnostic markers, implying that MDW could be an alternative biomarker and that the combination with qSOFA improves the diagnostic performance for early sepsis.

\section{Background}

Sepsis is one of the common reasons for patients to visit the emergency department (ED), hospital admission, and intensive care unit mortality(1). As early administration of antibiotics results in better clinical outcome(2-4), earlier detection helps in better sepsis management.

As the diagnosis of sepsis is made by clinical definition, a lot of clinical information is required for sepsis diagnosis. The detection of sepsis is often delayed because of the complexity of Sequential Organ Failure Assessment (SOFA) score. To overcome the complexity of SOFA, the Sepsis-3 group suggested using quick SOFA (qSOFA) score for rapid assessment. Although the qSOFA is a good indicator of mortality, it has limitations as a screening tool in $\operatorname{ED}(5)$. Therefore, the use of biomarkers in sepsis detection may be beneficial in decision making for further evaluation of sepsis. However, no biomarkers have been recommended in current sepsis guidelines.

Monocyte is one of the first responder to infection in blood and peripheral tissue and display functional and volumetric heterogeneity(6). During sepsis, functional re-programing between the monocyte and macrophage occurs(7), which induces morphological changes in the monocytes; the monocyte 
distribution width (MDW) reflects those changes and has been suggested as a marker of early sepsis in $\mathrm{ED}(8,9)$. However, the comparison of MDW with C-reactive protein (CRP) and procalcitonin (PCT), which are well-known biomarkers of sepsis, has been reported in few studies $(10,11)$.

Hence, our aim in this study was to evaluate the diagnostic value of MDW in sepsis and to compare it with other biomarkers such as white blood cell (WBC) count, CRP, PCT, and clinical score (qSOFA) used for detection of early sepsis.

\section{Methods}

\section{Study design and population}

From November 1, 2018 through July 1, 2019, patients who visited the emergency department (ED) enrolled prospectively in tertiary teaching hospital (Asan medical center, Seoul, Korea). The patients aged 18 to 80 were enrolled if the physician ordered complete blood count (CBC) with differential test for any reason. Patients who were pregnant, previously enrolled in this study due to multiple visits, and had invalid laboratory results (non-reportable MDW because of excessive debris, low monocyte count [less than 100], or presence of " $R$ " flag for differential results) were excluded. The patients were followed during ED stay, and categorized into six groups: control (non-infection), infection, systemic inflammatory response syndrome (SIRS), sepsis, severe sepsis, septic shock according to Sepsis-2 criteria (12). The description of each group is as follows: (1) non-infection: patients without any evidence of infection and zero or one SIRS criteria, (2) infection: patient with evidence of infection but zero or one of SIRS criteria, (3) SIRS, (4) sepsis: infection + SIRS, (5) severe sepsis: sepsis + evidence of organ dysfunction or tissue hypoperfusion, and (6) septic shock: severe sepsis + hypotension not reversed with fluid resuscitation. After enrollment of patients and data collection, we recategorized the enrolled patients into three groups: non-infection, infection, and sepsis. The description of each group is as follows: (1) non-infection: patients without any evidence of infection, (2) infection: patients with evidence of infection (positive blood culture or serology test also when the clinician suspected infection by clinical diagnosis), and (3) sepsis: patients with evidence of infection and the SOFA score being higher than two points, according to Sepsis-3 criteria(13). Thus, we could test the effectiveness of MDW and other biomarkers with both sepsis criteria. The subgroup analysis for diagnostic performance were done according to patient's immune status. Immune-compromised patients were patients with malignancy, neutropenic status (neutrophil counts less than $1,500 / \mu \mathrm{L}$ ), diagnosed as acquired immune deficiency syndrome or taking immune-suppressant agents due to solid organ or bone marrow transplantation.

\section{Data collection and laboratory marker measurement}

We collected the clinical data (previous medical history, results of imaging test, results of culture studies, vital signs, managements in ED, and medication details, etc.) from electronic medical record and the results of the laboratory tests in ED. Blood samples collected in K2 EDTA tubes (type of the tubes and vendor) within 4 hours at ED were used in the sample analysis. MDW was measured using an automatic blood cell analyzer DxH 900 (Beckman Coulter, Inc, Brea, California, USA) with the blood sample taken for 
baseline CBC test. The CRP (Roche CRPL3 by Cobas c702 module, Roche Diagnostics, Basel, Switzerland) and PCT (ADVIA Centaur Procalcitonin by ADVIA Centaur XPT, Siemens Healthcare Diagnostics Inc. USA) results were obtained from the blood collected in SST tubes within $4 \mathrm{~h}$ at ED.

\section{Study outcome and statistical analysis}

The primary aim of this study was to test the diagnostic accuracy of biomarkers and its comparison with area under the curve (AUC) of receiver operating characteristic (ROC) curve. The secondary aim was to test the diagnostic performance of combination of biomarkers, and clinical score. We used SPSS for Windows version 21.0 (SPSS Inc., Chicago, IL, USA) and MedCalc $®$ (MedCalc Software, Ostend, Belgium) medical software in this analysis. Continuous variables were presented as mean \pm standard deviation (SD) (for normally distributed variables) or median with the interquartile range (for non-normally distributed variables). Categorical variables were presented as percentage with numbers. To compare baseline characteristics of three groups for Sepsis-3 and four groups for Sepsis-2, ANOVA was used for continuous variables with normal distribution and the chi-square test or Fisher's exact test used for categorical variables. To determine optimal cut-off values of MDW, CRP, and PCT, we used Youden index from ROC curves analysis in a univariate model. Diagnostic performance of biomarkers was assessed in terms of sensitivity, specificity, positive predictive value, negative predictive value, positive likelihood ratio and negative likelihood ratio with $95 \%$ confidential intervals (Cl) by using cut-off value derived from a previous cohort trial(9) or optimal cut-off values from this study's cohort. Comparison of diagnostic performance among inflammatory markers and qSOFA for sepsis was done by AUC of ROC curve with $95 \% \mathrm{Cl}$. The results were considered as statistically significant when the two-tailed $p$-value was less than 0.05 .

\section{Results}

\section{Patients characteristics}

During the study period, in total, 695 patients were enrolled when the physician recommended CBC with differential in ED, from which, patients who were pregnant or previously enrolled (due to the multiple ED visit during study period) or with invalid MDW results were excluded. Finally, 549 patients with CBC, MDW, CRP, and PCT data were included in the analysis in this study (Fig. 1.).

Baseline characteristics of the overall population according to Sepsis-3 classification are presented in Table 1. Mean age of the overall population was 59.2 years (SD, 13.3), and male patients accounted for $55 \%$ of the overall population. There were 267 patients $(48.6 \%)$ who had at least one active malignancy (almost half of the overall population); from which, 126 (23\%) were patients with metastatic disease, 19 (3.5\%) were with hematologic malignancy, and 119 (21.3\%) were treated with cytotoxic chemotherapy within 2 weeks, before ED visit. The median SOFA score of the cohort at ED was 1 (Q1-Q3, 1-3). We assessed the SOFA score two times during ED stay (initial SOFA and final SOFA), if available (in some cases, there was only one value because of the short duration of ED stay). We used the worst SOFA during ED stay to define sepsis. The sepsis group accounted for $34.2 \%$ of the overall population $(n=188)$. 
All inflammatory biomarkers showed the highest value in the sepsis group (Table 2 and Additional file, Supplementary Table 2).

Table 1

Baseline clinical characteristics of patients visiting emergency department.

\begin{tabular}{|c|c|c|c|c|c|}
\hline & $\begin{array}{l}\text { Total }(n= \\
549)\end{array}$ & $\begin{array}{l}\text { Non- } \\
\text { infection } \\
(n=229)\end{array}$ & $\begin{array}{l}\text { Infection } \\
(n=132)\end{array}$ & $\begin{array}{l}\text { Sepsis } \\
(n=188)\end{array}$ & $\begin{array}{l}P \\
\text { value }\end{array}$ \\
\hline Age, years, mean (SD) & $59.2(13.3)$ & $57.8(13.8)$ & $55.5(13.9)$ & $63.4(11.0)$ & $\hat{0}_{0.005}$ \\
\hline Sex, male, $n(\%)$ & $302(55.0)$ & $118(51.5)$ & $74(56.1)$ & $110(58.5)$ & 0.348 \\
\hline \multicolumn{6}{|l|}{ Previous medical condition, $n(\%)$} \\
\hline Malignancy & $267(48.6)$ & $79(34.5)$ & $71(53.8)$ & $117(62.2)$ & $<.005$ \\
\hline Neutropenia ${ }^{a}$ & $67(12.2)$ & $20(8.7)$ & $19(14.4)$ & $28(14.9)$ & 0.109 \\
\hline Use of antibiotics ${ }^{b}$ & $73(13.3)$ & $14(6.1)$ & $23(17.4)$ & $36(19.1)$ & $<.005$ \\
\hline Use of G-CSF & $49(8.9)$ & $12(5.2)$ & $16(12.1)$ & $21(11.2)$ & 0.036 \\
\hline \multicolumn{6}{|l|}{ Immune- compromised, $n(\%)$} \\
\hline HIV or organ transplant & $6(1.1)$ & $3(1.3)$ & $0(0)$ & $3(1.6)$ & 0.368 \\
\hline Chemotherapy $^{\mathrm{C}}$ & $117(21.3)$ & $34(14.8)$ & $30(22.7)$ & $53(28.2)$ & 0.004 \\
\hline CMI, median (IQR) & $4(2-6)$ & $\begin{array}{l}3.0(1.0- \\
5.0)\end{array}$ & $\begin{array}{l}3.0(2.0- \\
6.0)\end{array}$ & $\begin{array}{l}5.0(4.0- \\
7.8)\end{array}$ & $<.005$ \\
\hline SOFA score ${ }^{\mathrm{d}}$, median (IQR) & $1(1-3)$ & $1(1-2)$ & $1(1-1)$ & $3(2-5)$ & $<.005$ \\
\hline $\mathrm{qSOFA}^{\mathrm{d}}$, median (IQR) & $0(0-1)$ & $0(0-0)$ & $0(0-1)$ & $1(0-1)$ & $<.005$ \\
\hline 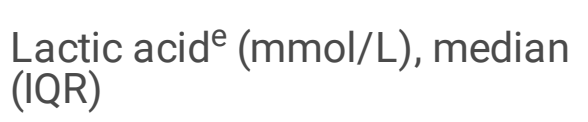 & $\begin{array}{l}1.4(1.0- \\
2.0)\end{array}$ & $\begin{array}{l}1.4(1.0- \\
1.9)\end{array}$ & $\begin{array}{l}1.1(0.8- \\
1.4)^{-}\end{array}$ & $\begin{array}{l}1.6(1.1- \\
2.1)\end{array}$ & $<.005$ \\
\hline \multicolumn{6}{|c|}{$\begin{array}{l}\text { SOFA, Sequential organ failure assessment score, qSOFA, quick Sequential organ failure assessment } \\
\text { score, ED emergency department, G-CSF, Granulocyte colony stimulating factor, IQR, interquartile } \\
\text { range, SD, standard deviation, CMI, Charson comorbidity index }\end{array}$} \\
\hline \multicolumn{6}{|c|}{ 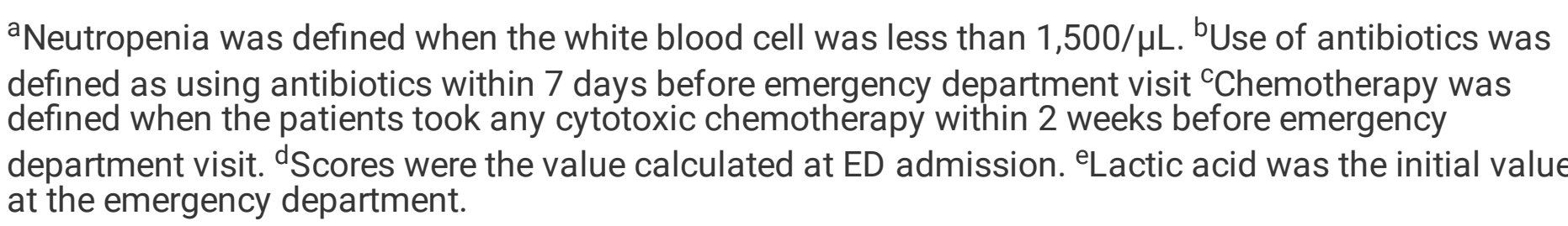 } \\
\hline
\end{tabular}


Table 2

Comparison of biomarker levels according to Sepsis-3 definition.

\begin{tabular}{|c|c|c|c|c|c|}
\hline & Total & $\begin{array}{l}\text { Non-infection } \\
(n=229)\end{array}$ & $\begin{array}{l}\text { Infection } \\
(n=132)\end{array}$ & $\begin{array}{l}\text { Sepsis } \\
(n=188)\end{array}$ & $\begin{array}{l}\mathrm{P} \\
\text { value }\end{array}$ \\
\hline $\begin{array}{l}\text { CRP }(\mathrm{mg} / \mathrm{dL}), \text { median } \\
\text { (IQR) }\end{array}$ & $\begin{array}{l}3.3(0.49- \\
9.08)\end{array}$ & $\begin{array}{l}0.52(0.1- \\
3.66)\end{array}$ & $\begin{array}{l}4.51(1.21- \\
10.02)\end{array}$ & $\begin{array}{l}6.70(2.79- \\
14.22)\end{array}$ & $<.005$ \\
\hline $\begin{array}{l}\text { PCT }(\mathrm{ng} / \mathrm{mL}) \\
\text { median (IQR) }\end{array}$ & $\begin{array}{l}0.05(0.05- \\
0.31)\end{array}$ & $\begin{array}{l}0.05(0.05- \\
0.098)\end{array}$ & $\begin{array}{l}0.05(0.05- \\
0.15)\end{array}$ & $\begin{array}{l}0.22(0.06- \\
1.05)\end{array}$ & $<.005$ \\
\hline $\begin{array}{l}\text { WBC }\left(x 10^{3} / \mathrm{uL}\right) \\
\text { median (IQR) }\end{array}$ & $\begin{array}{l}8.2(5.6- \\
11.6)\end{array}$ & $\begin{array}{l}7.5(5.3- \\
10.7)\end{array}$ & $\begin{array}{l}8.8(6.3- \\
12.4)\end{array}$ & $9.2(5.9-14.0)$ & 0.001 \\
\hline MDW, median (IQR) & $\begin{array}{l}21.5(18.0- \\
25.8)\end{array}$ & $\begin{array}{l}18.7(16.6- \\
23.5)\end{array}$ & $\begin{array}{l}21.5(19.0- \\
24.8)\end{array}$ & $\begin{array}{l}24.0(20.8- \\
27.8)\end{array}$ & $<.005$ \\
\hline
\end{tabular}

\section{Diagnostic performance according to Sepsis-3 definition}

The discriminatory function for sepsis (using sepsis-3 definition) did not show significant difference among inflammatory markers but WBC count (Fig. 2, Table 3). MDW with a cut-off value of 19.8 showed the highest sensitivity of $85.6 \%$ and negative predictive value of 0.867 among the tested biomarkers (CRP $69.7 \%, 0.839$ with $4.0 \mathrm{mg} / \mathrm{dL}$, and PCT $76.6 \%, 0.846$ with $0.05 \mathrm{ng} / \mathrm{mL}$; Table 3), which was observed when the cut-off value of 20.0 , obtained from a previous study(9). 
Table 3

Diagnostic performance of WBC count, CRP, PCT and MDW for sepsis (by SEPSIS-3 definition).

\begin{tabular}{|c|c|c|c|c|c|}
\hline & \multicolumn{2}{|l|}{ MDW } & CRP & РCT & WBC \\
\hline AUC & \multicolumn{2}{|l|}{0.71} & 0.75 & 0.76 & 0.61 \\
\hline$(95 \% \mathrm{Cl})$ & \multicolumn{2}{|l|}{$(0.67-0.75)$} & $\begin{array}{l}(0.71- \\
0.78)\end{array}$ & $\begin{array}{l}(0.72- \\
0.79)\end{array}$ & $(0.57-0.65)$ \\
\hline Cut-off & $19.8^{a}$ & $20.0^{\mathrm{b}}$ & $4.0^{\mathrm{a}}$ & $0.05^{a}$ & $\begin{array}{l}<4,000 / \mathrm{uL} \text { or }> \\
12,000 / \mathrm{uL}^{\mathrm{c}}\end{array}$ \\
\hline Sensitivity $(95 \% \mathrm{Cl})$ & $\begin{array}{l}85.6(85.5- \\
85.8)\end{array}$ & $\begin{array}{l}81.4(81.2- \\
81.6)\end{array}$ & $\begin{array}{l}69.7 \\
(69.5- \\
69.9)\end{array}$ & $\begin{array}{l}76.6 \\
(76.4- \\
76.8)\end{array}$ & $\begin{array}{l}49.5(49.2- \\
49.7)\end{array}$ \\
\hline Specificity $(95 \% \mathrm{Cl})$ & $\begin{array}{l}48.8(48.6- \\
48.9)\end{array}$ & $\begin{array}{l}50.7(50.5- \\
50.9)\end{array}$ & $\begin{array}{l}67.0 \\
(66.9- \\
67.2)\end{array}$ & $\begin{array}{l}67.2 \\
(67.1- \\
67.4)\end{array}$ & $\begin{array}{l}\text { 72.6(72.4- } \\
72.7)\end{array}$ \\
\hline \multirow{2}{*}{$\begin{array}{l}\text { Positive predictive } \\
\text { value }(95 \% \mathrm{Cl})\end{array}$} & \multirow{2}{*}{$\begin{array}{l}0.465 \\
(0.463- \\
0.467)\end{array}$} & \multirow{2}{*}{$\begin{array}{l}0.462 \\
(0.461- \\
0.464)\end{array}$} & 0.524 & 0.550 & 0.484 \\
\hline & & & $\begin{array}{l}(0.522- \\
0.526)\end{array}$ & $\begin{array}{l}(0.548- \\
0.552)\end{array}$ & $(0.482-0.487)$ \\
\hline \multirow{2}{*}{$\begin{array}{l}\text { Negative predictive } \\
\text { value }(95 \% \mathrm{Cl})\end{array}$} & \multirow{2}{*}{$\begin{array}{l}0.867 \\
(0.866- \\
0.868)\end{array}$} & \multirow{2}{*}{$\begin{array}{l}0.839 \\
(0.838- \\
0.841)\end{array}$} & 0.809 & 0.846 & 0.734 \\
\hline & & & $\begin{array}{l}(0.808- \\
0.811)\end{array}$ & $\begin{array}{l}(0.845- \\
0.847)\end{array}$ & $(0.732-0.735)$ \\
\hline Positive LR (95\% Cl) & $\begin{array}{l}1.67(1.66- \\
1.68)\end{array}$ & $\begin{array}{l}1.65(1.64- \\
1.66)\end{array}$ & $\begin{array}{l}2.11 \\
(2.10- \\
2.13)\end{array}$ & $\begin{array}{l}2.34 \\
(2.32- \\
2.35)\end{array}$ & $\begin{array}{l}1.80(1.79- \\
1.82)\end{array}$ \\
\hline Negative LR (95\% Cl) & $\begin{array}{l}0.29(0.29- \\
0.30)\end{array}$ & $\begin{array}{l}0.37(0.36- \\
0.37)\end{array}$ & $\begin{array}{l}0.45 \\
(0.45- \\
0.46)\end{array}$ & $\begin{array}{l}0.35(0.35- \\
0.35)\end{array}$ & $\begin{array}{l}0.70(0.70- \\
0.71)\end{array}$ \\
\hline \multicolumn{6}{|c|}{$\begin{array}{l}\text { MDW, monocyte distribution width; WBC, white blood cell; CRP, C-reactive protein; PCT, procalcitonin; } \\
\text { Cl, confidential interval; LR, likely hood ratio }\end{array}$} \\
\hline
\end{tabular}

When we excluded the immune-compromised patients, MDW of immune-competent patients indicated AUC of $0.74(95 \% \mathrm{Cl}, 0.67-0.79)$. Other biomarkers demonstrated the AUC $0.82(95 \% \mathrm{Cl}, 0.76-0.88)$ for CRP, $0.85(95 \% \mathrm{Cl}, 0.80-0.90)$ for PCT, and $0.66(95 \% \mathrm{Cl}, 0.60-0.72)$ for WBC.

In immune-compromised patients, there was no significant difference among AUC of biomarkers; 0.66 (95\% Cl, 0.62-0.71) for MDW, $0.66(95 \% \mathrm{Cl}, 0.61-0.72)$ for CRP, $0.682(95 \% \mathrm{Cl}, 0.63-0.73)$ for PCT, and $0.56(95 \% \mathrm{Cl}, 0.51-0.62)$ for WBC. There was a trend for weakening of AUC when compared to that in immune-competent patients (Table 4). 
Table 4

Diagnostic performance of WBC count, CRP, PCT and MDW for sepsis according to immune status.
MDW
CRP
PCT
WBC

Immune-compromised ${ }^{\mathrm{C}}(n=307)$

\begin{tabular}{|c|c|c|c|c|}
\hline $\operatorname{AUC}(95 \% \mathrm{Cl})$ & $\begin{array}{l}0.661(0.6- \\
0.721)\end{array}$ & $\begin{array}{l}0.660(0.599- \\
0.721)\end{array}$ & $\begin{array}{l}0.698(0.638- \\
0.758)\end{array}$ & $0.563(0.498-0.628)$ \\
\hline Cut-off value & $21.97^{a}$ & $4^{\mathrm{a}}$ & $0.05^{\mathrm{a}}$ & $\begin{array}{l}<4000 / \mathrm{uL} \text { or }> \\
12,000 / \mathrm{uL}^{\mathrm{b}}\end{array}$ \\
\hline $\begin{array}{l}\text { Sensitivity } \\
(95 \% \mathrm{Cl})\end{array}$ & 73.3(73.0-73.5) & $70.2(70.0-70.5)$ & $\begin{array}{l}74.0(73.8- \\
74.3)\end{array}$ & $48.9(48.6-49.1)$ \\
\hline $\begin{array}{l}\text { Specificity } \\
(95 \% \mathrm{Cl})\end{array}$ & $\begin{array}{l}55.1(54.9- \\
55.3)\end{array}$ & $\begin{array}{l}55.7(55.4- \\
55.9)\end{array}$ & $56.3(56.0-56.5)$ & $63.1(62.8-63.3)$ \\
\hline
\end{tabular}

Immune-competent ${ }^{\mathrm{d}}(n=242)$

\begin{tabular}{|c|c|c|c|}
\hline $\operatorname{AUC}(95 \% \mathrm{Cl})$ & $\begin{array}{l}0.732(0.662- \\
0.802)\end{array}$ & $\begin{array}{l}0.820(0.764- \\
0.876)\end{array}$ & $0.670(0.62-0.757)$ \\
\hline
\end{tabular}

Cut-off value

$18.99^{a}$

$4 \S$

$0.05^{\star}$

$<4000 /$ uL or $>$ $12,000 / \mathrm{uL}$

Sensitivity

$(95 \% \mathrm{Cl})$

Specificity

$(95 \% \mathrm{Cl})$
82.5(82.1-

82.8)

57.8(57.6-

58.1)
$68.4(68.0-68.8)$

$77.8(77.6-$

78.0)
82.5(52.1-

82.8)

78.3(78.1-

78.5)
$50.9(50.5-51.3)$

81.6(81.4-81.8)

MDW, monocyte distribution width; WBC, white blood cell; CRP, C-reactive protein; PCT, procalcitonin; $\mathrm{Cl}$, confidential interval.

aThe cut-off value was adopted from the value maximizing Youden index

${ }^{b}$ The cut-off value for WBC was adapted from the definition of systemic inflammatory response syndrome

Immune-competent was defined as patients otherwise immune-compromised

dImmune-compromised is defined as patients with have any malignancy, treated with G-CSF, neutropenia, taken organ transplantation or acquired immune deficiency syndrome

\section{Combination of biomarkers and clinical score}

We tested the diagnostic performance of combination of MDW and other biomarkers. When MDW was combined with WBC, CRP, or PCT, there was no improvement in the AUC of ROC curve (Additional file, Supplementary Table 3). However, when combined with qSOFA, the combination of MDW and WBC count showed significant improvement in diagnostic performance (Table 5). 
Table 5

Comparison of discriminative performance of biomarkers combined with qSOFA.

\begin{tabular}{|c|c|c|c|c|c|c|}
\hline & qSOFA & $\begin{array}{l}\text { MDW and } \\
\text { qSOFA }\end{array}$ & $\begin{array}{l}\text { WBC and } \\
\text { qSOFA }\end{array}$ & $\begin{array}{l}\text { CRP and } \\
\text { qSOFA }\end{array}$ & $\begin{array}{l}\text { PCT and } \\
\text { qSOFA }\end{array}$ & $\begin{array}{l}\text { qSOFA, } \\
\text { WBC and } \\
\text { MDW }\end{array}$ \\
\hline \multicolumn{7}{|l|}{$\begin{array}{l}\text { All patients ( } n \\
=549)\end{array}$} \\
\hline $\operatorname{AUC}(95 \% \mathrm{Cl})$ & $\begin{array}{l}0.67(0.62- \\
0.72)\end{array}$ & $\begin{array}{l}0.76(0.72- \\
0.80)\end{array}$ & $\begin{array}{l}0.69(0.64- \\
7.34)\end{array}$ & $\begin{array}{l}0.77(0.73- \\
0.81)\end{array}$ & $\begin{array}{l}0.76(0.72- \\
0.81)\end{array}$ & $\begin{array}{l}0.78(0.74- \\
0.82)\end{array}$ \\
\hline \multicolumn{7}{|l|}{$\begin{array}{l}\text { Immune- } \\
\text { competent }{ }^{\mathrm{a}}(n \\
=242)\end{array}$} \\
\hline $\operatorname{AUC}(95 \% \mathrm{Cl})$ & $\begin{array}{l}0.70 \\
(0.62- \\
0.78)\end{array}$ & $\begin{array}{l}0.70(0.61- \\
0.79)\end{array}$ & $\begin{array}{l}0.68(0.58- \\
0.77)\end{array}$ & $\begin{array}{l}0.74 \\
(0.65- \\
0.82)\end{array}$ & $\begin{array}{l}0.70(0.61- \\
0.79)\end{array}$ & $\begin{array}{l}0.71(0.62- \\
0.80)\end{array}$ \\
\hline \multicolumn{7}{|l|}{$\begin{array}{l}\text { Immune- } \\
\text { compromised }^{\mathrm{b}} \\
(n=307)\end{array}$} \\
\hline $\operatorname{AUC}(95 \% \mathrm{Cl})$ & $\begin{array}{l}0.66(0.59- \\
0.72)\end{array}$ & $\begin{array}{l}0.74(0.69- \\
0.80)\end{array}$ & $\begin{array}{l}0.66(0.60- \\
0.73)\end{array}$ & $\begin{array}{l}0.71(0.66- \\
0.77)\end{array}$ & $\begin{array}{l}0.74(0.69- \\
0.80)\end{array}$ & $\begin{array}{l}0.74(0.69- \\
0.80)\end{array}$ \\
\hline \multicolumn{7}{|c|}{$\begin{array}{l}\text { MDW, monocyte distribution width; WBC, white blood cell; CRP, C-reactive protein; PCT, procalcitonin; } \\
\mathrm{Cl} \text {, confidential interval; qSOFA, quick Sequential organ failure assessment }\end{array}$} \\
\hline \multicolumn{7}{|c|}{ aImmune-competent was defined as patients otherwise immune-compromised } \\
\hline
\end{tabular}

\section{Diagnostic performance under Sespsis-2 definition}

Baseline characteristics of patients according to sepsis-2 criteria and diagnostic performance for sepsis have been presented in Additional file (Supplementary Table 4 and Supplementary Table 5, respectively). Based on Sepsis-2 definition, in total, 245 patients were categorized as sepsis ( $n=245,44.6 \%)$. The diagnostic performance was demonstrated as AUC $(95 \% \mathrm{Cl})$ of $0.70(0.66-0.74)$ for MDW, $0.69(0.65-$ $0.72)$ for $W B C, 0.72(0.68-76)$ for PCT, and $0.79(0.75-0.82)$ for CRP.

\section{Discussion}

In this study, we tested the diagnostic performance of MDW for sepsis and compared it with that of conventional biomarkers (CRP, PCT, and WBC count). The diagnostic performance of MDW was presented in terms of AUC $(0.71,95 \% \mathrm{Cl}: 0.67-0.75)$, and compared with that of CRP $(0.75,0.71-0.78)$, PCT $(0.76$, $0.72-0.79)$, and WBC count $(0.61,0.57-0.65)$. The cut-off value of MDW in this study was 19.8 . It is similar to 20.0 (9) and 20.5 (8), observed in previous studies. Furthermore, MDW showed $85.6 \%$ of 
sensitivity with its optimal cut-off value from the study cohort and it was higher than that of CRP $(69.7 \%)$ and PCT (76.6).

Despite the SOFA score being good for differentiating the prognosis of sepsis, the time for gathering the information needed to assess SOFA may impede early sepsis diagnosis. In this regard, there have been many endeavors to find simple screening tool that would act as a good biomarker of sepsis(14-17), but none of them had shown superiority over others.

Among numerous biomarkers recommended for sepsis, CRP and PCT are the most widely used in clinical practice(17). CRP is an acute phase reactant produced by hepatocytes and increases within the first 6 to $8 \mathrm{~h}$ and peaks after $48 \mathrm{~h}$. It has been suggested as a sepsis marker(11) but has also been found to increase in various medical conditions(18). PCT is a good biomarker of sepsis(19) and increases earlier than $\operatorname{CRP}(20)$; it also has an advantage in the management of antibiotics(21).

Since the monocytes are rapid responders of infection, Crouser ED et al. suggested MDW as a novel biomarker of sepsis under the definition of Sepsis-2(8). Additional study(9) showed that MDW was also effective under the Sepsis-3 definition. In this study, we analyzed the efficacy of MDW based on Sepsis-3 and Sepsis-2 also compared it with other biomarkers. When comparing the diagnostic performance under Sepsis-3 definition, MDW was not inferior to CRP or PCT in terms of AUC. Regarding the sensitivity with optimal cutoff from the cohort, MDW showed higher sensitivity than other markers.

In the present analysis, the AUC of all biomarkers showed weak accuracy in sepsis diagnosis; this might be because we enrolled patients regardless of immune status. We did not exclude immune-compromised patients (malignancy, cytotoxic chemotherapy, neutropenia, or other disease and drug status which affects the immune status) to reflect the real-world practice.

Additional analysis was done according to immune status. As we expected, it appeared that the diagnostic performance of MDW was affected by immune status. From the diagnostic performance for Sepsis-3, according to immune status, we observed a trend that the AUC of biomarkers was lower in immune-compromised patients than in immune-competent patients. The optimal cut-off value of MDW for sepsis was higher for immune-compromised (22.0) than for immune-competent (19.0) patients.

The AUC of ROC was not significantly different among biomarkers for patients with different immune statuses. The significant changes were, however, observed across different septic conditions regardless of the immune status except for WBC count (Additional file, Supplementary Table 2), which suggests that MDW is changed by septic condition while being affected by immune status. The number of immunecompromised patients was relatively higher (over $50 \%$ of overall population) in our cohort, compared to that in previous publications, where patients with compromised immune cell function comprised only around $17 \%$ of the study population(9). This difference might explain the lower AUC of current analysis compared to that observed in previous reports $(8,9)$. The additional analysis of immune-competent patients showed the AUC $(0.73,95 \% \mathrm{Cl}, 0.66-0.80)$ was comparable with that of previous data (AUC 0.73 , $95 \% \mathrm{Cl}, 0.69-0.76)(9)$. The AUC of MDW was higher in immune-competent patients than in immune- 
compromised patients, suggesting that MDW would be more beneficial in patients not having these conditions: malignancy, chemotherapy, immune-suppressant, and organ-transplantation. Altogether, MDW may be a useful marker of sepsis but should be interpreted with caution according to patient's immune status.

Although, in previous studies the potential benefit of combining MDW with WBC $(8,9)$ was reported, combined effects of MDW on WBC, CRP, and PCT were disappointing in this analysis (Additional file, Supplementary Table 3). Even the well-known combination of the sepsis markers CRP and PCT(22) did not improve the AUC $(0.74,95 \% \mathrm{Cl}: 0.70-0.79)$ to beyond that achieved with the single marker (CRP 0.75 , $0.71-0.78]$ or PCT $[0.76,0.82-0.79])$. This suggested that with the WBC count and MDW, which can be obtained simultaneously, additional test for CRP and PCT does not have advantages in sepsis diagnosis. It is important to mention that despite the slightly higher AUC, PCT and CRP showed relatively lower sensitivity at the optimal cut-off values of 0.05 (sensitivity of $76.6 \%(95 \% \mathrm{Cl} 76.4-76.8 \%)$ ) and 4.0 (sensitivity of $69.7 \%(95 \% \mathrm{Cl} 69.5-69.9))$, respectively.

When combined with clinical score (qSOFA), MDW with WBC and CRP showed significant improvement in diagnostic accuracy in terms of AUC. In current guideline, the suggested algorithm for identifying sepsis uses the qSOFA for first assessment. MDW takes shorter laboratory test time than CRP or PCT and uses same blood specimen and test equipment with CBC test. Moreover, the qSOFA can be calculated in real time in clinical practice. The combination of MDW with WBC and qSOFA may provide effectiveness and convenience as an initial screening test.

We also conducted the analysis of biomarkers' performance with Sepsis-2 criteria. Among the tested biomarkers, CRP showed the highest AUC of ROC $(0.79,95 \% \mathrm{Cl}$ : $0.75-0.82)$. When MDW was combined with WBC, the performance was comparable to that of CRP and PCT. The overall AUC of ROC was not significantly different from that of Sepsis-3 definition.

\section{Strength}

Previous studies, in which MDW was evaluated, the primary focus was to check the effectiveness MDW in the detection of sepsis and its validation $(8,9)$ and to compare with other inflammatory markers, that is, PCT and $\operatorname{WBC}(8,9,23)$. We collected not only the CBC data (WBC count and MDW) but also the conventional biomarkers such as CRP and PCT, while Polilli et al.(23) compared MDW with PCT but in limited number; CRP was not present in that study. Moreover, we compared the biomarkers with qSOFA and the combinations. We collected data from patients with various immune statuses and performed additional analysis according to the immune status to differentiate patients who would potentially benefit from determining MDW.

\section{Limitations}

There are some limitations that need to be considered while interpreting the results. First, we enrolled the patients when the physicians recommended CBC-Diff; thus, there was risk of selection bias. In ED, 
patients who got laboratory test done were selected according to the physicians' decision; non-infection group in this population were more likely to have an underlying disease (e.g., $34.5 \%$ of patients could have had any kind of malignancy) compared to real control (normal). Second, this was a single-center

study; hence, there could be high pre-test probability of sepsis. However, the primary outcome of the study was comparison of the diagnostic performance based on AUC, which does not account for prevalence of disease. Third, because of the limited information on baseline medical conditions before the ED visit, we used the worst SOFA score in ED to diagnose sepsis; this might have resulted in incorrect SOFA score (e.g., patients with previous liver disease, renal disease or hematologic disease could have had a higher SOFA score), which could have resulted in misclassification bias. In general, there is limited information about baseline organ function for most of the patients in ED; hence, the results of our study may reflect the real-world's practice.

Sepsis is not a single disease but a clinical syndrome. Hence, there is no perfect standard for sepsis diagnosis and there is always a risk of misdiagnosis. Considering the risk of overdiagnosis (24), the biomarker of sepsis needs to be sensitive because of poor clinical outcomes of delayed diagnosis. As earlier intervention (antibiotics and fluid resuscitation) results in better outcome in sepsis management, rapid and easily available screening tools are highly beneficial for patients with sepsis. MDW showed relatively higher sensitivity, negative predictive value, and better diagnostic performance compared to conventional inflammatory markers. Hence, when combined with WBC and qSOFA, more accurate discrimination for sepsis is possible. With CBC test, MDW may help physicians to be observant about the sepsis and proceed with further steps required for evaluating the septic condition, thus facilitating early intervention for sepsis.

\section{Conclusions}

MDW, which can be measured with $\mathrm{CBC}$, is comparable with conventional biomarkers such as CRP and PCT; hence, it could be an early marker of sepsis and help to decide further evaluation of sepsis. When combined with the clinical score (qSOFA), more powerful diagnostic performance could be achieved.

\section{Abbreviations}

ANOVA: Analysis of variance; Cl: Confidential interval; CRP: C-Reactive protein; ED: Emergency department; G-CSF: Granulocyte colony stimulating factor; LR: Likelihood ratio; MDW: monocyte distribution width; PCT: procalcitonin; SD, Standard deviation, SOFA, Sequential organ failure assessment; qSOFA, quick sequential organ failure assessment; WBC, White blood cell; AUC: Area under the curve; ROC, Receiver operating characteristic; NPV: negative predictive value; PPV: positive predictive value;IQR: interquartile range, $\mathrm{CBC}$ : complete blood count

\section{Declarations}

\section{Ethical approval}


We conducted the study in accordance with the principle of the declaration of Helsinki. This study was approved by the local regional ethics board (Institutional review board, IRB number Ethics committee of the Asan. No. 2018-1159).

\section{Consent for publication}

Not applicable

\section{Availability of data and materials}

The datasets used and/or analysed during the current study are available from the corresponding author on reasonable request

Competing interest

None of the authors reported any conflicts of interest.

\section{Funding}

This study was supported by Beckman Coulter, Inc.

\section{Authors' contributions}

CJP, SBH, and DKO conceived and designed the study and supervised every aspect of the study. DKO was responsible for the ethical approval of the study. ALW took responsibility for data analysis, statistical analysis, and drafting the manuscript. CJP and SBH contributed equally as corresponding authors. All authors contributed to data interpretation and approved the final version before submission.

\section{Acknowledgments}

This study was supported by the Beckmann coulter. We also thank Elena Sukhacheva for her valuable advice and comments.

\section{References}

1. Kim J, Kim K, Lee H, Ahn S. Epidemiology of sepsis in Korea: a population-based study of incidence, mortality, cost and risk factors for death in sepsis. Clin Exp Emerg Med. 2019;6(1):49-63.

2. Liu VX, Fielding-Singh V, Greene JD, Baker JM, et al. The timing of early antibiotics and hospital mortality in sepsis. Am J Respir Crit Care Med. 2017;196(7):856-63.

3. Seymour CW, Kahn JM, Martin-Gill C, Callaway CW, et al. Delays from first medical contact to antibiotic administration for sepsis. Critical care medicine. 2017;45(5):759.

4. Chen HC, Lin WL, Lin CC, Hsieh WH, et al. Outcome of inadequate empirical antibiotic therapy in emergency department patients with community-onset bloodstream infections. J Antimicrob Chemother. 2013;68(4):947-53. 
5. Haydar S, Spanier M, Weems P, Wood S, et al. Comparison of QSOFA score and SIRS criteria as screening mechanisms for emergency department sepsis. The American Journal of Emergency Medicine. 2017;35(11):1730-3.

6. Arenson EB Jr, Epstein MB, Seeger RC. Volumetric and functional heterogeneity of human monocytes. J Clin Invest. 1980;65(3):613-8.

7. López-Collazo E, Cavaillon J-M, Biswas SK. Macrophages in Sepsis Progression. In: Macrophages: Biology and Role in the Pathology of Diseases Biswas SK, Mantovani A, editor.

8. Crouser ED, Parrillo JE, Seymour C, Angus DC, et al. Improved early detection of sepsis in the ED with a novel monocyte distribution width biomarker. Chest. 2017;152(3):518-26.

9. Crouser ED, Parrillo JE, Seymour CW, Angus DC, et al. Monocyte Distribution Width: A Novel Indicator of Sepsis-2 and Sepsis-3 in High-Risk Emergency Department Patients. Crit Care Med. 2019;47(8):1018-25.

10. Yentis SM, Soni N, Sheldon J. C-reactive protein as an indicator of resolution of sepsis in the intensive care unit. Intensive Care Med. 1995;21(7):602-5.

11. Póvoa P, Almeida E, Moreira P, Fernandes A, et al. C-reactive protein as an indicator of sepsis. Intensive Care Med. 1998;24(10):1052-6.

12. Dellinger RP, Levy MM, Rhodes A, Annane D, et al. Surviving Sepsis Campaign: International Guidelines for Management of Severe Sepsis and Septic Shock, 2012. Intensive Care Med. 2013;39(2):165-228.

13. Singer M, Deutschman CS, Seymour CW, Shankar-Hari M, et al. The third international consensus definitions for sepsis and septic shock (Sepsis-3). Jama. 2016;315(8):801-10.

14. Parlato M, Philippart F, Rouquette A, Moucadel V, et al. Circulating biomarkers may be unable to detect infection at the early phase of sepsis in ICU patients: the CAPTAIN prospective multicenter cohort study. Intensive Care Med. 2018;44(7):1061-70.

15. Chan T, Gu F. Early diagnosis of sepsis using serum biomarkers. Expert Rev Mol Diagn. 2011;11(5):487-96.

16. Gilfillan M, Bhandari V. Neonatal sepsis biomarkers: where are we now? Research Reports in Neonatology. 2019;9:9.

17. Pierrakos C, Vincent JL. Sepsis biomarkers: a review. Crit Care. 2010;14(1):R15.

18. Landry A, Docherty P, Ouellette S, Cartier LJ. Causes and outcomes of markedly elevated C-reactive protein levels. Can Fam Physician. 2017;63(6):e316-23.

19. Meynaar IA, Droog W, Batstra M, Vreede R, et al. In Critically III Patients, Serum Procalcitonin Is More Useful in Differentiating between Sepsis and SIRS than CRP, II-6, or LBP. Crit Care Res Pract. 2011;2011:594645-5.

20. Brunkhorst FM, Heinz U, Forycki ZF. Kinetics of procalcitonin in iatrogenic sepsis. Intensive Care Med. 1998;24(8):888-9. 
21. Huang DT, Yealy DM, Filbin MR, Brown AM, et al. Procalcitonin-Guided Use of Antibiotics for Lower Respiratory Tract Infection. N Engl J Med. 2018;379(3):236-49.

22. Ruan L, Chen GY, Liu Z, Zhao Y, et al. The combination of procalcitonin and C-reactive protein or presepsin alone improves the accuracy of diagnosis of neonatal sepsis: a meta-analysis and systematic review. Crit Care. 2018;22(1):316.

23. Polilli E, Sozio F, Frattari A, Persichitti L, et al. Comparison of Monocyte Distribution Width (MDW) and Procalcitonin for early recognition of sepsis. PLOS ONE. 2020;15(1):e0227300.

24. Rhee C, Chiotos K, Cosgrove SE, Heil EL, et al: Infectious Diseases Society of America Position Paper: Recommended Revisions to the National Severe Sepsis and Septic Shock Early Management Bundle (SEP-1) Sepsis Quality Measure. Clin Infect Dis 2020.

\section{Figures}

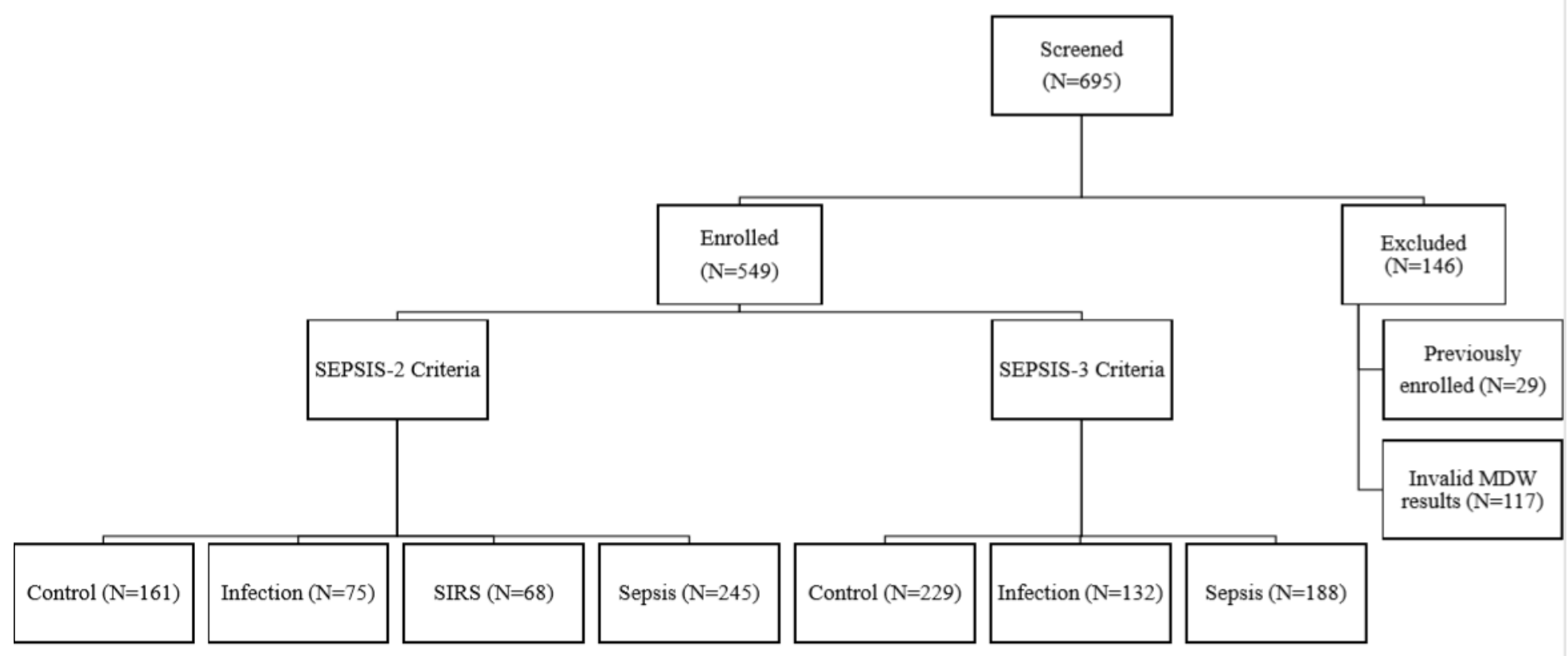

Figure 1

Flow of the study. *For patients with invalid MDW results, MDW could not be measured because of agranulocytosis or regional flag. 


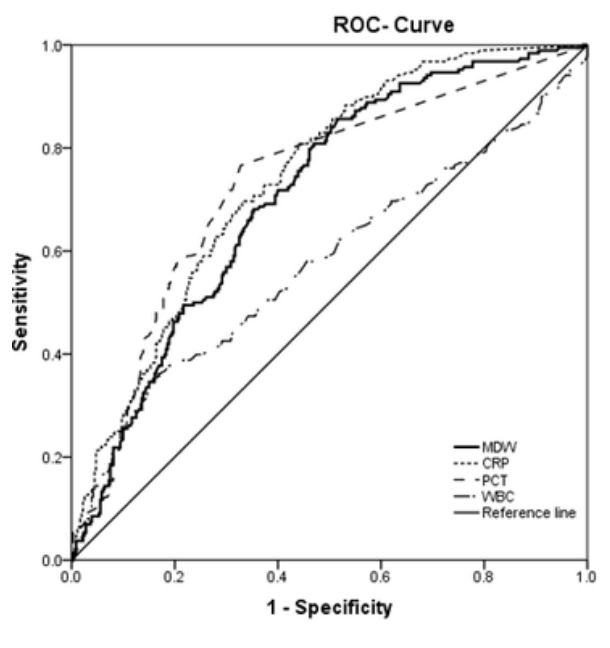

(a)

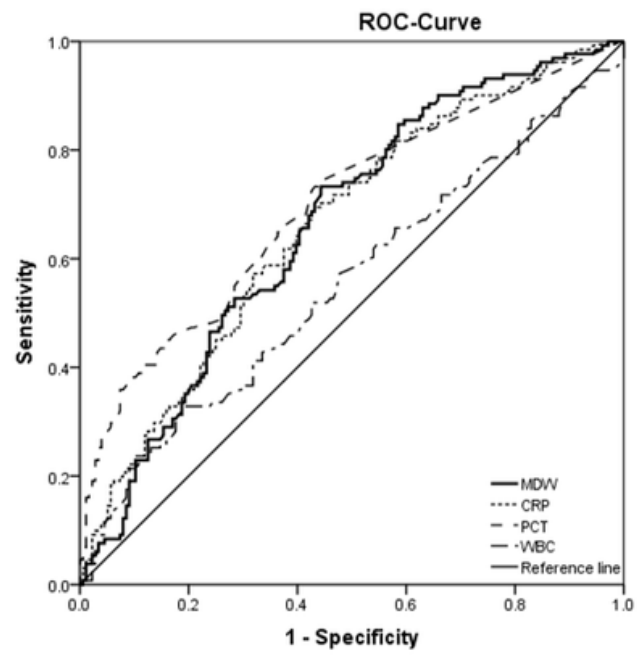

(b)

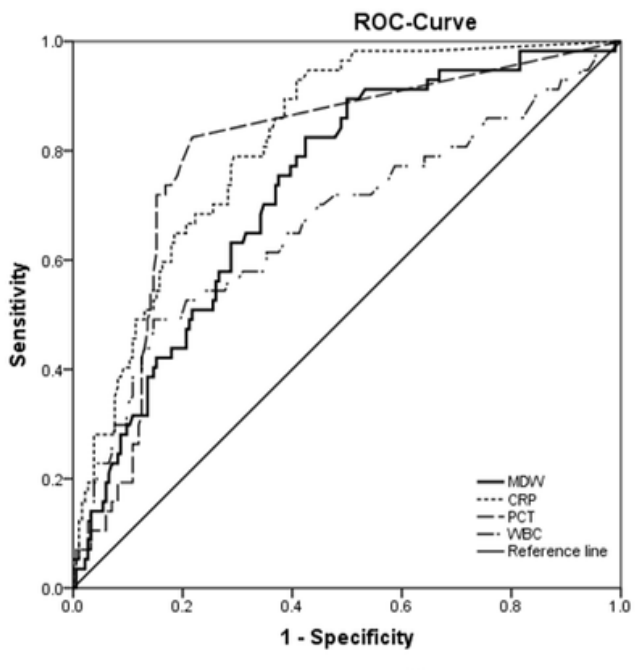

(c)

Figure 2

AUC of ROC curve for sepsis, according to immune status. (a) Overall population. WBC alone is inferior to other biomarkers. (b) Immune-compromised. (c) Immune-competent. Comparison of AUROC according to immune status showed that AUROC relatively higher in immune-competent patients. ROC: Receiver operating curve, AUC: Area under the curve, AUROC area under the curve of receiver operating curve. MDW, monocyte distribution width, CRP C-reactive protein, PCT procalcitonin, WBC White blood cell

\section{Supplementary Files}

This is a list of supplementary files associated with this preprint. Click to download.

- Additionalfile.docx 